\title{
A very sudden onset of tracheomalacia with an unknown cause
}

\author{
Mahvesh Rana Javaid, ${ }^{1}$ Kai Lee Tan, ${ }^{2}$ Yasser Noeman Ahmed ${ }^{3}$
}

${ }^{1}$ Barts \& The London School of Medicine and Dentistry, London, UK

${ }^{2}$ Department of Radiology, Bart's Health, London, UK ${ }^{3}$ Barts \& The London NHS Trust, London, UK

\section{Correspondence to} Dr Yasser Noeman Ahmed, yasser.ahmed@bartshealth.nhs. uk

\section{DESCRIPTION}

A 73-year-old man with a series of longstanding comorbidities, including diabetes mellitus, asthma, hypertension, chronic kidney disease and ischaemic heart disease, presented to accident and emergency with two episodes of collapse and exacerbation of asthma. Two weeks beforehand, the patient had just returned from a symptomless holiday in Bangladesh, with symptoms of cough, shortness of breath and acute onset of confusion arising a week later prior to admission. On examination, he was tachypnoeic with widespread polyphonic wheeze on auscultation but apyrexial.

He was stabilised and admitted on the basis of acute on chronic kidney injury with metabolic acidosis and possible low-respiratory tract infection. His treatment was started with augmentin, bronchodilators and steroids. Chest x-ray and blood cultures revealed to be clear. However suddenly, with 4 days of good recovery, metabolic acidosis worsened and the decreased creatine levels suddenly rose from 395 to $656 \mathrm{mmol} / \mathrm{l}$ over 1 week. Simultaneously, he suffered with atypical chest infection, urine output depletion and acute onset of severe confusion and agitation. The overall reason for acute kidney injury was sepsis, which lead to multiple organ failure. $\mathrm{He}$ was transferred to ITU for dialysis although all the vitals were stable, including $96 \%$ oxygen saturation on room air. He was referred for a non-contrast whole body CT under general anaesthesia. The CT

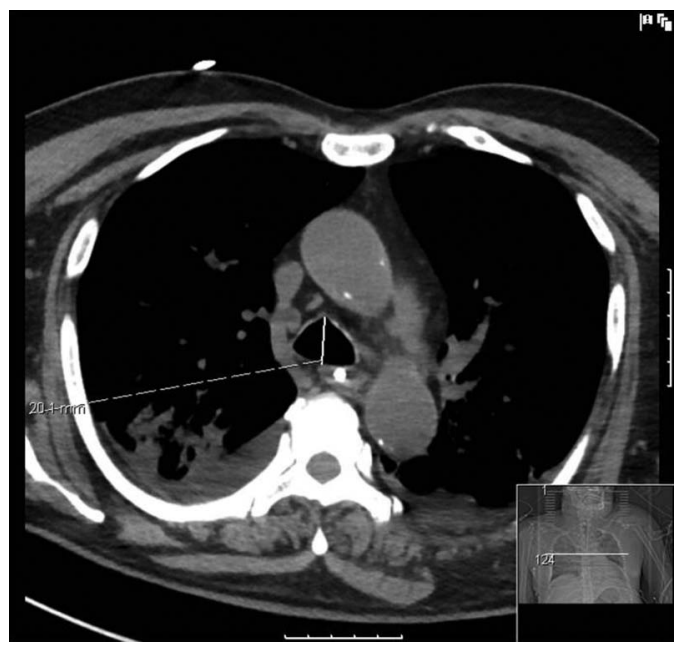

Figure 1 At level of azygous vein, non-contrast CT thorax show anterioposterior diameter of distal trachea, with nastrogastric tube in-situ as well as evidence of lower lobe consolidation. Patient is ventilated with lungs inflated at this stage.

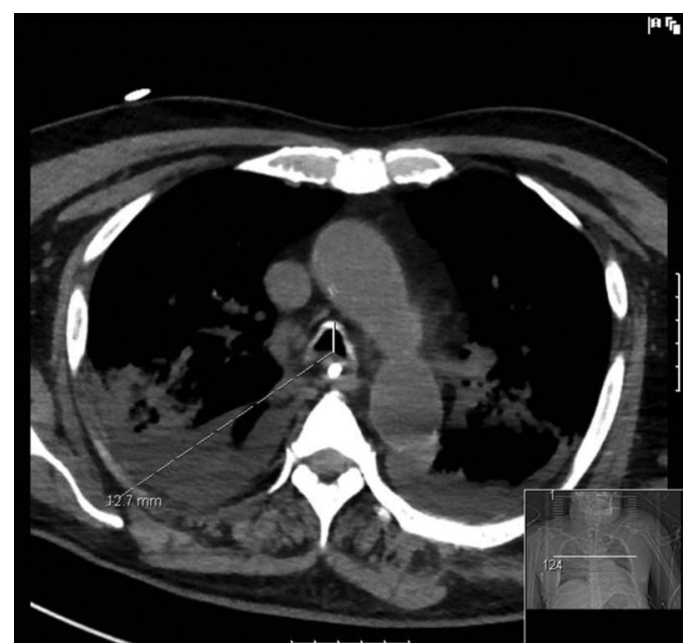

Figure 2 At same level, with lungs deflated, the distal trachea shows narrowing in its anterioposterior diameter as well as characteristic change in its configuration as shown.

thorax shockingly showed tracheomalacia (figure 1 and 2) at the level of azygous vein, and the rest of the CT was remarkable. He remained intubated and on dialysis, as he was not fit for surgery.

Going through literature research, the cause of this very sudden onset of tracheomalacia was unexplainable; especially as he did not experience tracheostomy or prolonged intubation before. The investigations for other existing causes of tracheomalacia included bronchoscopy with biopsies and CT scan, both of which did not show any of the suggested differential diagnosis. Other tests to investigate possible reflux and chronic obstructive pulmonary disease were impossible to perform in view of the critical care condition of the patient. Unfortunately, there was no possible long-term management as the patient passed away undergoing multiple organ failure, before having any surgery or stents.

\section{Learning points}

- The cause of a very sudden onset of tracheomalacia is very rare and has yet to be found.

- It is important to maintain an airway by intubation after diagnosis of tracheomalacia. 


\section{Images in...}

Contributors MRJ wrote the article and carried out the literature and amp; patient case research. YNA found the case and managed the case, and has been involved in reviewing the case where necessary. KLE has been involved in the providing figures of this case. YNA is the guarantor.
Competing interests None.

Patient consent Obtained.

Provenance and peer review Not commissioned; externally peer reviewed.

Copyright 2013 BMJ Publishing Group. All rights reserved. For permission to reuse any of this content visit

http://group.bmj.com/group/rights-licensing/permissions.

BMJ Case Report Fellows may re-use this article for personal use and teaching without any further permission.

Become a Fellow of BMJ Case Reports today and you can:

- Submit as many cases as you like

- Enjoy fast sympathetic peer review and rapid publication of accepted articles

- Access all the published articles

- Re-use any of the published material for personal use and teaching without further permission

For information on Institutional Fellowships contact consortiasales@bmjgroup.com

Visit casereports.bmj.com for more articles like this and to become a Fellow 